\title{
A new bile acid-derived lariat-ether: Design, synthesis and cation binding properties ${ }^{\text {II }}$
}

\author{
P BABU and UDAY MAITRA* \\ Department of Organic Chemistry, Indian Institute of Science, \\ Bangalore 560 012, India \\ e-mail: maitra@orgchem.iisc.ernet.in
}

\begin{abstract}
A new chola lariat ether (1, a 21-crown-6) was constructed from readily available precursors. The association constant of compound $\mathbf{1}$ with alkali metal picrates was measured using Cram's extraction protocol. Evidence is presented for the involvement of the 3-methoxy group for the complexation. Energy minimised structures show that the A-ring gets slightly distorted upon metal ion binding.
\end{abstract}

Keywords. Crown ether; chola crown; bile acid; metal ion binding.

\section{Introduction}

Crown ethers are a class of synthetic cyclic polyethers with structural resemblance to naturally occurring ion transporters like valinomycin and nonactin. ${ }^{1}$ During the past three decades a large number of reports on crown ethers have accumulated in the literature because of their potential application in phase transfer catalysis, ${ }^{2}$ ion transport, ${ }^{3}$ chromatography, ${ }^{4}$ chromogenic reagents, ${ }^{5}$ as metal ion sensors, ${ }^{6}$ membrane mimics ${ }^{7}$ and in chiral recognition, ${ }^{8}$ to mention a few. Lariat ethers ${ }^{9}$ belong to a special class of crown ethers with covalently linked side arm(s), which enhance the binding ability of the crown ethers towards metal ions. The unusual facially amphiphlic structure of bile acids has extensively been utilised in our laboratory to design and synthesise a number of crown ethers and their binding properties with alkali metal ions have been reported. ${ }^{10}$ In this paper, we report the design and synthesis of a new chola lariat ether 1 utilizing the curved backbone of cholic acid and differential reactivity of the well-separated $3 \alpha, 7 \alpha$ and $12 \alpha$ hydroxyl groups. Structural and binding studies with alkali metal ions are also reported.

\section{Results and discussion}

\subsection{Design}

In our earlier work, compound 2 (chart 1) having a pendant 1-pyrenyl group at C-12 showed (slightly) more selective binding towards $\mathrm{K}^{+}$and $\mathrm{Rb}^{+}$but did not show enhanced binding as we had anticipated, possibly due to the perpendicular positioning of the pyrene moiety with respect to the mean crown plane as indicated by the geometry minimised structure of compound 2 (figure $1 \mathrm{a})^{10 \mathrm{~b}, \mathrm{c}}$. We envisioned that a C-3 hydroxyl protected 7,12-crown might show enhanced binding towards alkali metal ions. Structure opti-

\footnotetext{
IIDedicated to Professor C N R Rao on his 70th birthday

*For correspondence
} 
misation $^{11}$ of compound 1 without (HF/3-21G* and DFT/B3LYP/6-31G*) and with $\mathrm{K}^{+}$ $\left(\mathrm{HF} / 3-21 \mathrm{G}^{*}\right)$ showed that the 3-methoxy group is located at the centre of the crown plane (figure 1b). The following structural changes were observed between minimised structures of compound $\mathbf{1}$ alone, and with $\mathrm{K}^{+}$ion: (1) in the presence of $\mathrm{K}^{+}$the 3-methoxy oxygen and four crown oxygen atoms coordinate with $\mathrm{K}^{+}(<3 \AA$ distance), and (2) the Aring of steroid backbone bends towards the crown ring presumably to maximize the interaction between the $3-\mathrm{OMe}$ and the bound $\mathrm{K}^{+}$. The calculated energies are shown in table 1. The computed structures of $\left(\mathbf{1}+\mathrm{K}^{+}\right)$are shown in three different views in figure 2 .

\subsection{Synthesis}

Compound 3 was synthesized from cholic acid as reported earlier. ${ }^{10 \mathrm{~b}}$ This was selectively methylated at the $3 \propto-\mathrm{OH}$ using $\mathrm{NaH} / \mathrm{MeI}$ under phase transfer conditions to furnish compound 4 (extension of the reaction time beyond $45 \mathrm{~min}$ resulted in the formation of di- and tri-methylated products). The treatment of compound 4 with NaH/pentaethylene-
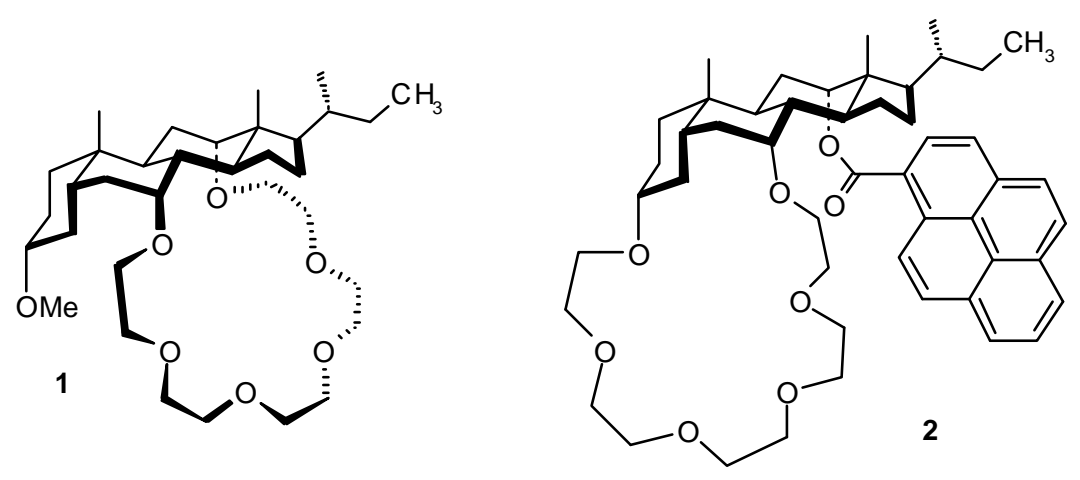

Chart 1.
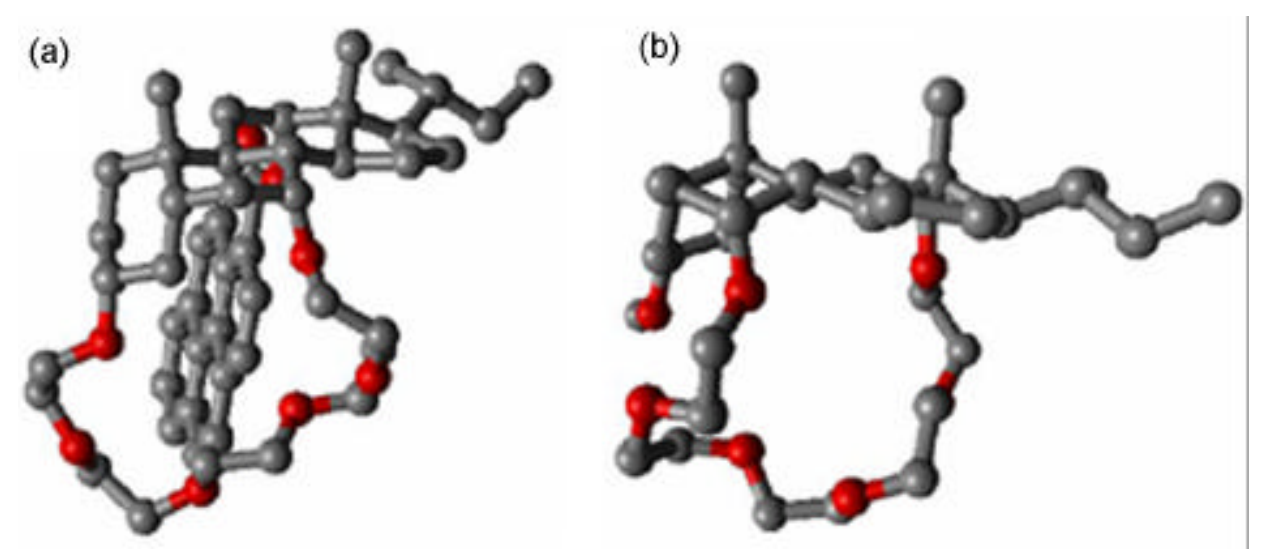

Figure 1. Minimised (gas-phase) structures of compounds (a) 2 and (b) 1. The hydrogen atoms have been omitted for clarity. 
Table 1. Total energy of the chola crown ethers without and with potassium ion calculated using SPARTAN (HF/3-21G*).

\begin{tabular}{lc}
\hline Compounds & Total energy (au) \\
\hline $\mathbf{1}$ & $-1836 \cdot 2357^{\mathrm{a}}$ \\
$\mathbf{1}+\mathrm{K}^{+}$ & $-2432 \cdot 4186$ \\
$\mathbf{2}$ & $-2516 \cdot 7552$ \\
$\mathbf{2}+\mathrm{K}^{+}$ & $-3112 \cdot 9272$ \\
\hline
\end{tabular}

${ }^{\mathrm{a}} \mathrm{DFT} / 6-31 \mathrm{G}^{*}$ calculation gave a value of -1858.2421 au
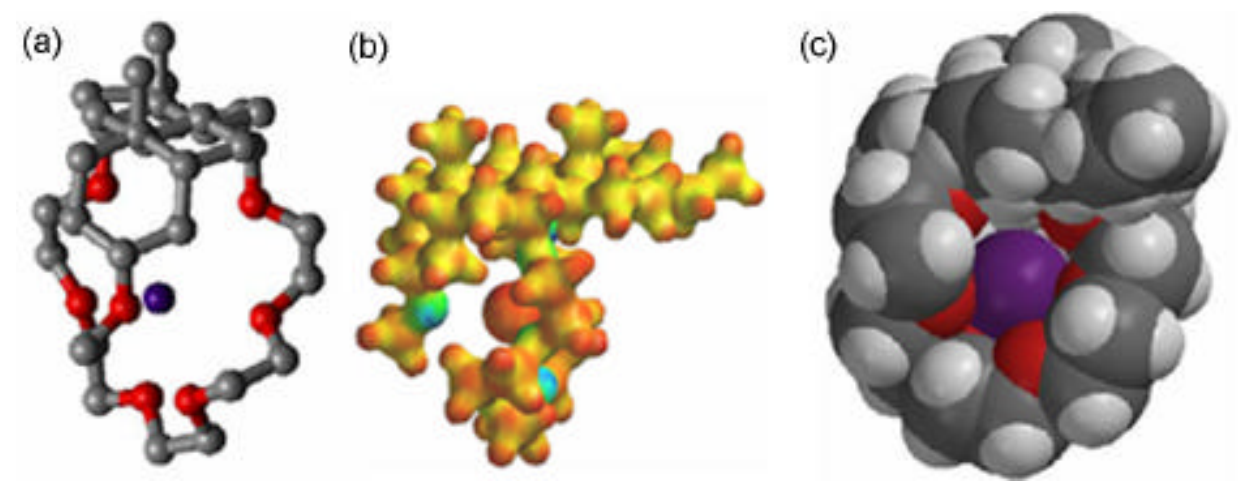

Figure 2. Minimised structures of $\mathbf{1}$ with $\mathrm{K}^{+}$: (a) view perpendicular to the crown ether plane from the A-ring side (without $\mathrm{H}$-atoms), (b) the potential surface viewed along the plane of the crown ether, (c) view of the space filling model perpendicular to the crown ether plane from the D-ring side.

glycol ditosylate under high dilution-reflux conditions afforded compound 1 (chola-21crown-6) in 34\% yield (scheme 1).

\subsection{Binding properties}

Association constants were measured in $\mathrm{CHCl}_{3}$ using Cram's extraction protocol ${ }^{12}$ using metal picrates. The binding constants are presented in table 2. Compound $\mathbf{1}$ showed enhanced binding towards alkali metal ions with slightly higher selectivity for $\mathrm{K}^{+}, \mathrm{Rb}^{+}$ and $\mathrm{Cs}^{+}$. The binding constants decreased in the order $\mathrm{Rb}^{+}>\mathrm{Cs}^{+}>\mathrm{K}^{+}>\mathrm{Na}^{+}>\mathrm{Li}^{+}$. The higher binding constants observed for crown ether $\mathbf{1}$ compared to compound $\mathbf{2}$ is presumably due to the additional stabilisation provided by the pendant $3 \propto$-methoxy group. In order to verify the coordination of the 3-methoxy group with the metal ion, a $\mathrm{CDCl}_{3}$ solution of crown ether $1(8.7 \mathrm{mM})$ was equilibrated with an equal volume of a $\mathrm{D}_{2} \mathrm{O}$ solution of $\mathrm{K}^{+}$picrate $(17.2 \mathrm{mM}) .{ }^{1} \mathrm{H}$ NMR of the $\mathrm{D}_{2} \mathrm{O}$ layer did not show peaks corresponding to the crown ether, whereas the $\mathrm{CDCl}_{3}$ layer showed $32 \%$ complex formation (by NMR integration). In the complex, the $3-\beta$ hydrogen peak shifted downfield by $0.02 \mathrm{ppm}$, which may result from the distortion of the A-ring. A (smaller) downfield shift of the 3-methoxy group $(0.005 \mathrm{ppm})$ is also consistent with the interaction suggested by our model. 

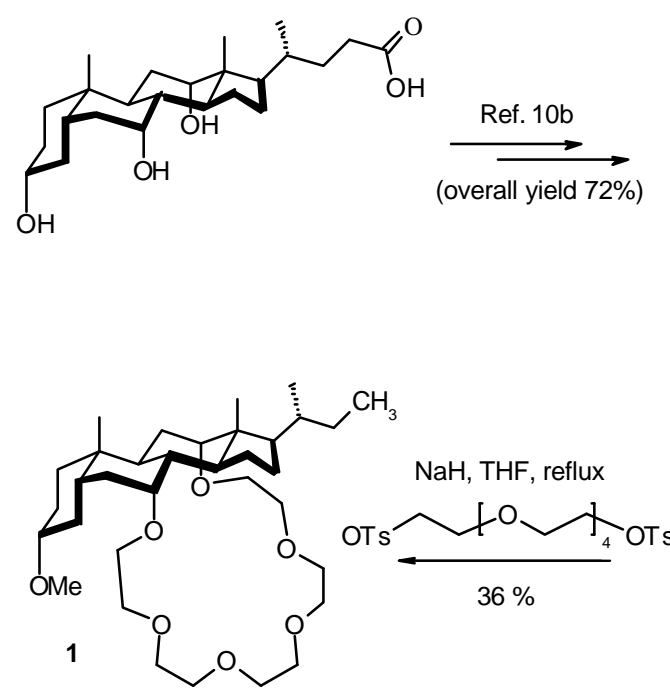

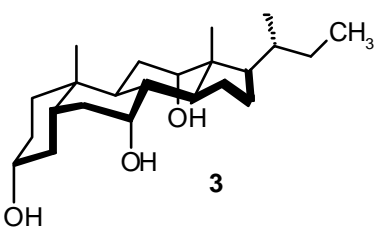

(a) $\mathrm{NaH}, \mathrm{THF}, 0^{\circ} \mathrm{C}$

(b) TBAI, Mel, $35^{\circ} \mathrm{C}$ $75 \%$

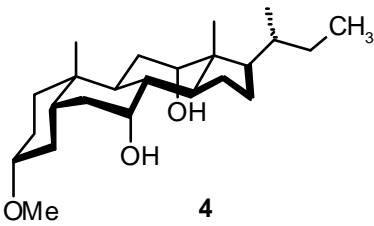

Scheme 1.

Table 2. Association constants of alkali metal ions with 1 in $\mathrm{CHCl}_{3}$ at $25^{\circ} \mathrm{C}$ by Cram's method.

\begin{tabular}{lccccc}
\hline \multirow{2}{*}{$\begin{array}{l}\text { Chola } \\
\text { crown }\end{array}$} & \multicolumn{5}{c}{ Binding constant $\left(\log K_{a}\right)$} \\
\cline { 2 - 6 } & $\mathrm{Li}^{+}$ & $\mathrm{Na}^{+}$ & $\mathrm{K}^{+}$ & $\mathrm{Rb}^{+}$ & $\mathrm{Cs}^{+}$ \\
\hline $\mathbf{1}$ & $5 \cdot 10$ & 5.85 & 6.20 & 6.33 & 6.28 \\
$\mathbf{2}$ & $4 \cdot 17$ & 4.56 & 5.68 & 5.54 & 4.83 \\
\hline
\end{tabular}

\section{Experimental}

Melting points were recorded in open capillaries and are uncorrected. ${ }^{1} \mathrm{H}$ NMR spectra were recorded on a JEOL Lambda-300 spectrometer. Unless otherwise stated ${ }^{1} \mathrm{H}$ NMR were recorded in $\mathrm{CDCl}_{3}$ using TMS as the internal standard. LRMS spectra were recorded in JEOL LMS_DX 303 with JEOL JMA-DA mass data system, MALDI-TOF MS were recorded on a Kompack Seq model (Kratos Analytical, UK) fitted with a nitrogen laser, HRMS spectra was recorded in Q-TOF micro. Infrared spectra were recorded on a Jasco FT-IR-410 spectrometer. All reactions were conducted under dry nitrogen and stirred magnetically. Reaction temperatures refer to external or bath temperatures. Thin layer chromatography was performed using precoated plates (silica gel 60F-254) purchased from Sigma. These plates were stained either with iodine vapour or with Lieberman-Bucchardt reagent. Purification of the products were usually done using gravity columns. All solvents were purified and distilled before use. Toluene, benzene and tetrahydrofuran were distilled from sodium/benzophenone ketyl.

\subsection{3 -Methoxy-7 $\alpha, 12 \alpha$ dihydroxy-24-nor-cholane (4)}

To a suspension of $\mathrm{NaH}(\sim 50 \%$ dispersion, $558 \mathrm{mg}, 11.6 \mathrm{mmol})$ in THF $(10 \mathrm{ml})$, compound $3(1.1 \mathrm{~g}, 3 \mathrm{mmol})$ was added under an argon atmosphere, and stirred at $0^{\circ} \mathrm{C}$. 
After $1 \mathrm{~h}$, a reflux condenser was fitted, tetrabutylammonium iodide $(160 \mathrm{mg}, 0.43 \mathrm{mmol})$ and iodomethane $(0.56 \mathrm{mM}, 9 \mathrm{mmol})$ were added and the mixture was warmed to $35^{\circ} \mathrm{C}$. After $45 \mathrm{~min}$, the reaction mixture was quenched with $\mathrm{AcOH}(0.5 \mathrm{ml})$, extracted with EtOAc $(25 \mathrm{ml})$, washed with water $(50 \mathrm{ml})$, saturated $\mathrm{NaHCO}_{3}$ solution $(30 \mathrm{ml})$ and brine $(25 \mathrm{ml})$ and dried over anhyd. $\mathrm{Na}_{2} \mathrm{SO}_{4}$. The crude product was purified by column chromatography on silica gel $(2 \mathrm{~cm} \times 25 \mathrm{~cm})$ using $25-40 \%$ EtOAc/pet ether mixture, to mg $(75 \%)$ of the product. m.p.: $1447 \quad{ }^{\circ} \mathrm{C}$.

IR (neat, $\left.\mathrm{cm}^{-1}\right): 3454(s), 2937(s), 2870(s), 1464(m), 1374(m), 1093(s), 759(s) .{ }^{1} \mathrm{H}$ NMR $\left(300 \mathrm{MHz}, \mathrm{CDCl}_{3}\right): 3.99(s, 1 \mathrm{H}), 3.8(\mathrm{br} s, 1 \mathrm{H}), 3.34(s, 3 \mathrm{H}), 3.07-298(\mathrm{~m}$

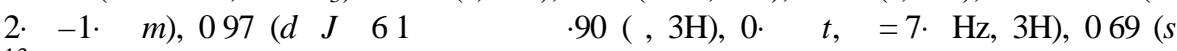
${ }^{13} \mathrm{C}$ NMR $\left(75 \mathrm{MHz}, \mathrm{CDCl}_{3} \quad .57,7296,68 . \quad .45,4713,46 . \quad 00,4145\right.$, $3972,36 . \quad .87,3519,35 . \quad .58,2829,28 . \quad .42,2684,26 . \quad 20,2268$, 17 12, 12 . 42. LRMS: $342\left({ }^{+}-2 \mathrm{H}_{2} \mathrm{O}\right), 253(100 \%)$.

3.2 3 $\alpha$-Methyloxy-24-nor-chola-21-crown-6 (1)

To a refluxing suspension of $\mathrm{NaH}(\sim 50 \%$ dispersion, $113 \mathrm{mg}, 2.3 \mathrm{mmol})$ in dry THF $(25 \mathrm{ml})$, a solution of $4(149 \mathrm{mg}, 0.390 \mathrm{mmol})$ and pentaethyleneglycol ditosylate ( $216 \mathrm{mg}, 0.4 \mathrm{mmol})$ in dry THF $(15 \mathrm{ml})$ was added dropwise over a period of $34 \mathrm{~h}$ under argon. The resulting solution was refluxed for an additional $35 \mathrm{~h}$. The reaction mixture was concentrated, diluted with $\mathrm{CHCl}_{3}(25 \mathrm{ml})$, quenched with $\mathrm{AcOH}(0.5 \mathrm{ml})$, washed with water $(20 \mathrm{ml})$ and dried over anhyd. $\mathrm{MgSO}_{4}$. The crude product was purified by column chromatography on silica gel $(3 \mathrm{~cm} \times 25 \mathrm{~cm})$ by eluting with $40-75 \%$ EtOAc/pet ether mixture. The title compound $(15 \mathrm{mg}, 34 \%$ based on recovered starting material) was obtained as a viscous liquid.

IR (neat, $\left.\mathrm{cm}^{-1}\right)$ : $2929(s), 2864(s), 1459(m), 1372(m), 1104(s) .{ }^{1} \mathrm{H}$ NMR (300 MHz, $\left.\mathrm{CDCl}_{3}\right)$ : 3.85-3.63 $(\mathrm{m}), 3.47(\mathrm{~s}, 1 \mathrm{H}), 3.33(\mathrm{~s}, 3 \mathrm{H}), 3.25(\mathrm{~m}, 1 \mathrm{H}), 3.00(\mathrm{~m}, 1 \mathrm{H}), 2.20-0.95$ $(m, 22 \mathrm{H}), 0.91(d, J=7.5 \mathrm{~Hz}, 3 \mathrm{H}), 0.90(s, 3 \mathrm{H}), 0.84(t, J=7.2 \mathrm{~Hz}, 3 \mathrm{H}), 0.65(s, 3 \mathrm{H}) .{ }^{13} \mathrm{C}$ NMR $\left(75 \mathrm{MHz}, \mathrm{CDCl}_{3}\right)$ : 80.96, 80.77, 76.30, 71.42, 71.38, 70.98, 70.93, 70.86, 70.80, $70 \cdot 72,70 \cdot 66,69 \cdot 16,68 \cdot 71,55 \cdot 26,46 \cdot 24,42 \cdot 39,41 \cdot 88,39 \cdot 63,37 \cdot 00,35 \cdot 26,34 \cdot 72,28 \cdot 72$, $28 \cdot 33,27 \cdot 89,27 \cdot 53,26 \cdot 88,23 \cdot 16,22 \cdot 91,22 \cdot 73,17 \cdot 32,12 \cdot 38,10 \cdot 61$. MALDI-TOF: $603 \cdot 8$ (Calc. $\mathrm{M}+\mathrm{Na}$ 603.42) and 619.8 (Calc. $\mathrm{M}+\mathrm{K}$ 619.397). HRMS (ES-TOF): 619.3958 (Calc. M + K 619.3976).

\section{Conclusions}

chola lariat ether.

1 showed greater binding with alkali metal ions compared to $-7]$ crown . The enhanced binding may be due to an additional stabilization of crownion complex by the 3-

chiral recognition properties of this molecule.

This wor

Scientific Research. Bangalore. PB thanks the Council of Scientific and Industrial Research, New Delhi for financial support. 


\section{References}

1. Painter G R and Pressman B C 1982 Top. Curr. Chem. 10183

2. (a) De Ruiter C and Lingeman H 1997 Hand book of phase transfer catalysis 405; (b) Regen S L 1975 J. Am. Chem. Soc. 975956

3. Costero A M, Villarroya J P, Gil S, Aurell M J and Ramirez de M C 2002 Tetrahedron 58 6729

4. (a) Hyun M H 2003 J. Sep. Sci. 26 242; (b) Blasius E and Janzen K P 1982 Pure Appl. Chem. 542115

5. (a) Inerowicz H D $2001 \mathrm{~J}$. Incl. Pheno. Macro. Chem. 39 211; (b) Takagi M and Uneo K 1984 Top. Curr. Chem. 12139

6. (a) He H, Mortellaro M A, Leiner M J P, Young S T, Fraatz R J and Tusa J K 2003 Anal. Chem. 75 549; (b) de Silva A P, Gunaratne H Q N, Gunnlaugsson T, Huxley A J M, McCoy C P, Rademacher J T and Rice T E 1997 Chem. Rev. 971515

7. Echegoyen L E, Portugal L, Miller S R, Heranandez J C, Echegoyen L and Gokel G W 1988 Tetrahedron Lett. 294065

8. Nishi A, Ikeda A, Matsuda T and Shinkai S 1991 J. Chem. Soc., Chem. Commun. 339

9. Gokel G W, Dishing D M and Diamond C J 1980 J. Chem. Soc., Chem. Commun. 1053

10. (a) Maitra U and Bag B G 1994 J. Org. Chem. 59 6114; (b) Maitra U, D’Souza L J and Kumar V P 1998 Supramol. Chem. 10 97; (c) More recent structure optimisation of compound 2 in the presence of $\mathrm{K}^{+}$showed a different orientation of the pyrene ring

11. Spartan '02, Wavefunction, Inc. Irvine, CA, USA

12. Newcomb M, Moore S S and Cram D J 1977 J. Am. Chem. Soc. 996398 